\title{
Improving long-term forest ecology research for the 21st century
}

\author{
by R.A. Lautenschlager ${ }^{1}$
}

Changes in scientific views, approaches, and the public's environmental concerns have broadened the foci of silvicultural research from individuals in stands to these plus other interacting components at broader temporal and spatial scales. Present studies have benefited from increasing interdisciplinary ecological study; however, even the most interdisciplinary research and management could be improved by (1) moving beyond public comment to incorporating the public's environmental concerns into experimental and management designs; (2) being conducted at scales (time and space) that are appropriate to ecosystem components of greatest concern; (3) encouraging researchers and managers to test their knowledge using landscape-level forest vegetation management and checking predictions using sufficient monitoring; and (4) recognizing that within-study integration will require identifying study-appropriate integrative currencies.

Key words: ecosystem research, integrative currency, landscape, monitoring, public values, scale, solutions

\section{Introduction}

The value of long-term silvicultural research and management may be reduced if: (1) the public's environmental concerns are ignored when designing these experiments; (2) the scales (time and space) examined are not operationally, ecologically, and socially meaningful; (3) they lack operational hypothesis testing; and (4) they lack a unifying approach to within-study scientific integration. In this paper I briefly discuss these potential problems and some proposed solutions. I do not believe, however, that the problems discussed here apply to all research and management. Rather, the value of some or all of the solutions proposed should be judged based on individual study objectives. Throughout this paper I reference "components of concern." These can be identified in a variety of ways, but here they are based on Lautenschlager's (1998) "Identify the Specifics" approach, designed to identify socially/ecologically integrated, specific abiotic and biotic resources associated with management practices and ecosystem types of concern.

\section{Potential Problem Areas and Solutions}

The examples of potential problems and proposed solutions outlined below are not exhaustive, but serious attention to these areas could help improve public acceptability of operational management and research, and where appropriate, make results more meaningful to managers and the scientific community.

\footnotetext{
${ }^{1}$ Ontario Ministry of Natural Resources, Ontario Forest Research Institute, 1235 Queen Street East, Sault Ste. Marie, Ontario P6A 2E5. E-mail: lautenr@gov.on.ca
}

Les changements dans la vision scientifique, les approches, et l'interet du public pour les questions environnementales ont elargi le domaine de la recherche sylvicole pour passer des arbres dans des peuplements aux arbres ainsi que les autres composantes en interaction a des echelles plus grandes de temps et de d'espace. Les etudes actuelles ont beneficie de l'etude ecologique interdisciplinaire sans cesse en evolution; toutefois la plupart des recherches et gestions interdisciplinaires pourraient etre ameliorees (1) en allant au-dela des commentaires du public pour incorporer ses interets environnementaux dans la conception experimentale et la gestion; (2) en les menant a des echelles (temps et espace) qui sont appropriees aux composantes de les ecosystemes qui ont le plus d'interet; (3) en encourageant les chercheurs et les gestionnaires a tester leurs connaissances en utilisant l'amenagement de la vegetation forestiere au niveau du paysage et en verifiant les predictions par l'entremise d'une surveillance adequate; et (4) en reconnaissant que l'integration en cours d'etude necessitera une identification des valeurs integrantes appropriees a l'etude.

Mots-cles: recherche ecosystemique, valeur integrante, paysage, surveillance, valeurs publiques, echelle, solutions

Example 1: The public's environmental knowledge and concerns are ignored when designing research and management experiments

Public concern about forest management in northern forested ecosystems, which commonly focuses on non-fibre forest products (Thompson and Welsh 1993), is not limited to

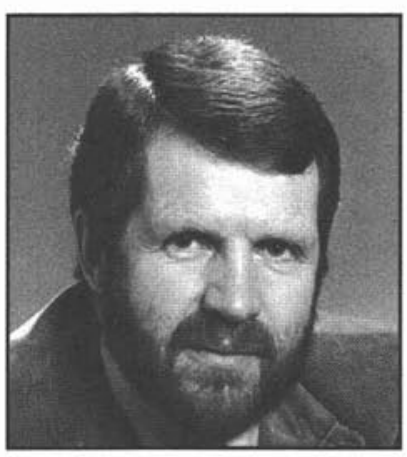
environmental activists (Moore 1995). Rather it comes from a variety of publics and differs based on gender, age, income, occupation, and the degree to which an individual's or the community's well-being is associated with their dependence on forestry and forest products for jobs or environmental values (Wagner et al. 1998). Although forest scientists realize that social values are continually changing and that the public increasingly expects to play a larger role in forest management planning (Shindler 1998, Weyerhaeuser 1998), few have attempted to (1) document similarities, differences, and changes through time in what identifiable publics want from forest research or management; and (2) determine whether spokespersons claiming to represent the public actually do. In addition, except for responding to concerns raised by environmental activists, few researchers or managers have attempted to understand and address the public's environmental concerns about research and specific management practices. As scientists, we often assert that public concerns about natural resource management practices could be reduced if the public were educated (if they "knew what we know") or that review and com- 
ment, rather than participation in formulating plans, are appropriate mechanisms for involving the public.

\section{Solution?}

Generalized public education has not alleviated concern about forest management. For instance, spokespersons for forest industry and policy groups have tried to use information to combat criticism and philosophical differences. That information, however, has been questionable and is increasingly questioned by knowledgeable groups and individuals who understand that it can be interpreted in a variety of ways. Therefore, as noted by Weyerhaeuser (1998), technical answers (education) will likely be unacceptable if we can't answer their philosophical questions. So, although education appropriately transfers practical, factual information, it is an inappropriate, potentially counterproductive way to communicate with publics about their forest management-related environmental concerns.

To ensure that natural resource management integrates public desires as well as biological and economic needs, communication rather than education is required. I've suggested that natural resource managers should start by gathering information about the public's environmental concerns at local scales, using standardized organizational (e.g., resource, management practice, ecosystems of concern) and ecological frameworks (eco-section, district, region, zone) designed to cross spatial scales (Lautenschlager 1998).

Specifically, I've suggested a framework where (1) local "experts," recognized as such by the community, identify and prioritize resources, management practices, and ecosystems of concern; (2) local concerns, organized across established ecological land classification systems, provide input for broader-scale "expert" review and comment; and (3) these reviews and modifications lead to the establishment of biopolitical (balancing ecological, social, and economic considerations), scale-appropriate (local, regional, provincial, etc.), research priorities and indicators of sustainability (Lautenschlager 1998). After this process is completed, forest scientists and managers should consult that output as they work with local communities to design and implement management scenarios to achieve landscape-level, community-identified, biologically responsible (maintaining local and broader-scale biological components) needs over time (Lautenschlager 1996a).

Regardless of how it is acquired, input that honestly identifies the public's environmental concerns and is used in association with information about ecological needs and economic effects to design modified forest research and management will be a key to the success of research and management projects in the 21 st century. If the demand for public input into natural resource science and management decisions is not satisfied, then ecological research projects (short- or long-term) and the most ecologically sound management, regardless of merit or history, may suffer or die.

\section{Example 2. Scales (time and space) examined must be operationally, ecologically, and socially meaningful}

Baskerville (1994) suggested that most forest research is not used because the scientist and the practitioner have not agreed on an operational statement of the problem. As discussed in Example 1 (above), and suggested by Hanley (1994) and Shindler (1998), the public's environmental concerns have joined research and operations as major considerations when design- ing meaningful natural resource research and management. However, the addition of the social component makes what was already complex and poorly integrated (Baskerville 1994) even more difficult to achieve.

Fine-scale silviculture and forest ecology studies have been the norm; however they are inherently unable, or poorly able, to answer broader-scale, generally applied, realworld questions. In addition, advances in ecological understanding, including the importance of scales (space and time) and context (the spatial arrangement, adjacency and juxtaposition of forested patches across the landscape), that have surfaced during the last three decades have increased the difficulty of interpreting outcomes from field research. Thus, scientists are designing increasingly larger-scale, longer-term field studies, with at least one group using replicated 400 ha experimental units that will be examined for at least a century (Larsen $e t$ al. 1997), and paying closer attention to the influence of the landscape context on components of concern (nutrients, wildlife, scenic views, etc.).

Using larger-scale experimental units allows rigorous statistical tests of responses of some wildlife species and other major components of concern (e.g., soil nutrient losses). However, the elements of greatest concern to most hunters, naturalists, and conservation biologists (e.g., game species, large carnivores, raptors, and rare plants) commonly have home ranges or distributions that are too large and disjunct to be contained, much less replicated, in many of the larger-scale, stand-level studies that have been implemented during the last decade. Therefore, researchers involved in these studies often examine how other components (e.g., small mammals, songbirds, and indicator species like carabid beetles) respond to forest management. Although these second-choice components are biologically interesting, their indicator potential has been questioned (Noss 1994) and seems unwarranted, based on responses of species within these groups following several conifer release alternative treatments, no treatment, and unharvested controls (Lautenschlager et al. 1998). In addition, in my experience, except for songbirds, these groups are not a major concern of most publics.

Finally, minimal attention is being paid to crossing scales and designing stand-level research that will translate into landscape-level realities (Allen and Hoekstra 1992). We now understand that fine-scale (stand-level) disturbances have little effect on broad-scale (landscape-level) variables (O'Neill et al. 1986). However, we continue to rely on stand-level research designs to identify management systems that deliver multiple resource outputs from stands, when sustainable multiple outputs are most likely to come from different places, geographical or successional, across the landscape.

\section{Solution?}

Specific research questions determine the appropriate scales of study in space and time. Some forest research (e.g., the effects of ice damage and potential remedial treatments to speed recovery of damaged sugar maple stands) is appropriately conducted at the tree and stand level. Other questions (e.g., the effects of forest harvesting on woodland caribou populations or climate change on white pine distribution) require much broader-scale manipulations and understanding. Adaptive management (Holling 1978, Walters 1986, Walters and Holling 1990, Lee 1993) seems to provide an appropriate frame- 
work for operational studies designed to answer key sociallygrounded management-related questions at appropriate scales. Walters (1998), however, notes that the success rate of adaptive management implementation has been low, and Kendall and Nichols (1998) suggest that if learning is the focus, then more traditional management experiments are preferable to adaptive management. "Predictive adaptive management," based on identifying community desires for landscape-level management through time, integrating them with technical ecological knowledge about potential concerns and achievement of identified outputs, monitoring results, and obtaining feedback at several stages, may also be used to advance socially responsible forest ecosystem management (Lautenschlager 1996a).

Although few examples of successful uses of the approaches outlined above exist, adaptive or predictive adaptive management will likely be required to address the scale-related concerns and to provide the landscape-scale context required to document the effects of management across landscapes on often wide-ranging components of concern, such as large carnivores. Whatever approach they take, if forest researchers and managers are to provide meaningful results to policymakers, and the public, then they must begin to implement broader-scale (at least watershed-level) operational treatments.

Understanding the landscape context at a broad scale, the percentage of the landscape managed and how, and the placement of the managed and unmanaged units across landscapes within the area of interest will become increasingly important to understanding how management can be adjusted to maintain components of concern. In Ontario, for example, for every hectare of harvestable forest that has been cut, two hectares have been consumed by natural disturbances: fires, insects, and disease (D. Higgs, Silvicultural Technician, Forest Management Branch, Ontario Ministry of Natural Resources, personal communication). As we consider landscape-level management scenarios, we must understand how these disturbances are distributed over time and space, so that any practice designed to emulate natural disturbances - of questionable value, according to Meffe and Carroll (1997) - can be reduced where disturbances are primarily natural and increased, if appropriate, where disturbances are primarily human caused. Still, specific components of concern must be identified and continually updated to ensure that they are maintained through active management, if necessary, across the landscape and through time (Lautenschlager 1996b, 1998).

\section{Example 3. Research lacks operational, socially integrated hypothesis testing}

Franklin (1987) notes that although many sophisticated predictive models and general constructs exist, few have been tested against data (reality). The adaptive management literature suggests that management-related surprises should be expected; however, the history of forest management suggests that successes can also be expected. Still, researchers, myself included, repeatedly conduct management-related ecological field work as though they cannot predict the effects of treatments on specific environmental components of interest; they simply implement treatments and document responses. This approach (the Scientific Method) is appropriate when outcomes are unpredictable; however, barring major unforseen events, natural resource management-related outcomes are relatively predictable. Although we justify these studies by referring to other researchers using the same approach, we repeatedly fail to test management potentials and our predictive capabilities. As Franklin (1987) suggests, we conduct basic studies but rarely attempt the logical next step. In addition, although implementing extreme treatments may provide information about potential management limits, the focus on extreme rather than standard practices should be reconsidered. For instance, results from one study that used extreme cutting and vegetation control treatments (Bormann and Likens 1979) has been misinterpreted and used to restrict what are apparently benign standard operational practices (Lautenschlager et al. 1998).

\section{Solution?}

Researchers working with managers and the public should design operationally feasible management experiments that test their ability to predict and deliver a variety of specific natural resources from managed ecosystems through time. To achieve this goal, they must first identify, within a social context, the specific environmental components that will be retained or result from the management planned (Lautenschlager 1996a, 1998). Next, they must implement that management, monitor the implementation, monitor outcomes relative to the specific environmental resources identified, and compare those outcomes with their previous predictions. Finally, they must use the resulting information to improve their next generation of predictions (Lautenschlager 1996a). At the stand and sometimes at broader scales, forest and wildlife managers have, for decades, used this approach for single species; now they must use it to produce multiple benefits that define the desired future forest condition.

\section{Example 4. Even interdisciplinary research lacks a unifying approach to within-study integration}

Many multidisciplinary (i.e., scientists working independently in a common area) or interdisciplinary (scientists evaluating common treatments and exchanging information) studies have been established (Stelfox 1995, Hollstedt and Vyse 1997, Larsen et al. 1997, Lautenschlager et al. 1998, Oliver and Powers 1998). However, examples of integrated forestry research, where the individual components studied (e.g., insects) provide an integrated understanding of responses of other higher- (e.g., small mammals) or lower-level (e.g., vegetation) components are limited. Researchers working in the same study area may exchange information about two or more of the components being studied, but unless integration is designed into the study, these bits of information provide little understanding relative to responses of other components. Therefore, although correlations among components may exist, and GIS maps of distributions of multiple components can be prepared, cause and effect cannot be established.

\section{Solution?}

The value of both short- and long-term ecosystem studies will increase if inter-component integration is designed into these studies and cooperators actively participate in these multiple-component integrated experiments. Before a study is implemented, the research team must discuss and agree on the appropriate integration "currency" (e.g., energy/ha) to use to evaluate and connect the various ecosystem components. This currency could be geochemic, energetic, economic, etc., 
and will likely vary among studies and with the interests of the leaders, participants, and funders. After an integration currency has been identified, the research team can design the experiment and response measurements with an eye to documenting changes and transfers in the identified currency. Using more than one currency to provide additional integration increases the difficulty, but results could be presented in more than one relevant form (e.g., caloric and economic flows and outputs), thus greatly increasing the value of results.

\section{Conclusions}

Seventeen years ago Naisbitt (1982) predicted the increasing demand for public input into a variety of decisions previously made by trained professionals or elected leaders. Since then, referenda and legal challenges to natural resource management decisions have become common across North America. In the future, publics will have an even greater voice in natural resource management decisions. If natural resource researchers and managers also want a voice, they must start working with those publics to design the next generation of forest research and management experiments. In the past, stand-level studies were the standard. In the future, understanding landscapelevel consequences, and interactions, on management outcomes will become increasingly critical. Researchers and managers must start documenting and testing their knowledge of natural resource dynamics, monitoring outcomes from management experiments, and comparing outcomes with predictions so that they can continually adjust their knowledge. Finally, ecosystem researchers should begin to design integrated studies of management-related dynamics, the first step of which is to identify the appropriate integrative currency, which will depend on scientific interest, the questions being asked, the system(s) being studied, and the funder. Although these suggestions are likely not appropriate for all studies, they should be considered when new studies are being designed.

\section{Acknowledgements}

I thank Wendeline Price and Abby Obenchain for editorial comments on an earlier draft of this manuscript and two anonymous reviewers whose outstanding constructive comments enabled me clarify many points as I revised this manuscript.

\section{References}

Allen, T.F.H. and T.W. Hoekstra. 1992. Toward a Unified Ecology. Columbia University Press, New York.

Baskerville, G.L. 1994. Gaelic poetry for deaf seagulls-encore. For. Chron. 70(5): 562-564.

Bormann, F.H. and G.E. Likens. 1979. Pattern and process in a forested ecosystem. Springer-Verlag. New York.

Franklin, J.F. 1987. Importance and justification of long-term studies in ecology. In G.E. Likens (ed.). Long-term studies in ecology - Approaches and alternatives. pp. 3-19. Springer-Verlag, New York.

Hanley, T.A. 1994. Interaction of wildlife research and forest management: The need for maturation of science and policy. For. Chron. 70(5): 527-532.

Holling, C.S. 1978. Adaptive Environmental Assessment and Management. John Wiley, New York.

Hollstedt, C. and A. Vyse (eds.). 1997. Sicamous Creek Silvicultural Systems Project: Workshop (Apr. 24-25, 1996), Kamloops, B.C. Proceedings. Can. Res. Br., B.C. Min. For., Victoria, B.C. Work Pap. 24/1997.
Kendall, W.L. and J.D. Nichols. 1998. Management experiments versus adaptive resource management: Is there a difference? In Program and Abstracts. The Wildlife Society 5th Annual Conference (Sept. 22-26), Buffalo, NY. p. 99.

Larsen, D.R., S.R. Shifley, F.R. Thompson III, B.L. Brookshire, D.C. Dey, E.W. Kurzejeski and K. England. 1997. 10 guidelines for ecosystem researchers - Lessons from Missouri. J. For. 95(4): 4-9. Lautenschlager, R.A. 1996a. Predictive adaptive management - Applying natural resource management research. In Smith, C.R. and G.W. Cook (eds.). Advancing Boreal Mixedwood Management in Ontario. pp. 148-151. Workshop Proceedings published by Natural Resources Canada, Canadian Forest Service and the Ontario Ministry of Natural Resources, Sault Ste. Marie, ON.

Lautenschlager, R.A. 1996b. Identify the specifics: A biopolitical approach for establishing research priorities. J. For. 94(4): 31-34. Lautenschlager, R.A. 1998. From rhetoric to reality: Using specific environmental concerns to identify critical sustainability issues. Ecosystems 1(2): 176-182.

Lautenschlager, R.A., F.W. Bell, R.G. Wagner and P.E. Reynolds. 1998. The Fallingsnow Ecosystem Project: Documenting the consequences of conifer release alternatives. J. For. 96(11): 20-27.

Lee, K.N. 1993. Compass and Gyroscope: Integrating Science and Politics for the Environment. Island Press, Washington, DC.

Meffe, G.K. and C.R. Carroll. 1997. Principles of Conservation Biology, Second Edition. Sinauer Associates, Sunderland, Mass.

Moore, P. 1995. Pacific Spirit: The Forest Reborn. Terra Bella, West Vancouver, BC. 110p.

Naisbitt, J. 1982. Megatrends: Ten new directions transforming our lives. Warner, New York. 290p.

Noss, R.F. 1994. Maintaining ecological integrity in representative reserve networks. Draft report to the World Wildlife Fund Canada - Endangered Spaces Campaign. Toronto.

Oliver, W.W. and R.F. Powers. 1998. Black Mountain, California: Interdisciplinary field research in ponderosa pine. J. For. 96(8): 4-9.

O'Neill, R.V., D. L. DeAngelis, J.B. Waide and T.F.H. Allen. 1986. A hierarchical concept of ecosystems. Princeton University Press, Princeton.

Shindler, B. 1998. Does the public have a role in forest management? Canadian and U.S. perspectives. For. Chron. 74(5): 700-702.

Stelfox, J.B. (ed.) 1995. Relationships between stand age, stand structure, and biodiversity in aspen mixedwood forests in Alberta. Alberta Environment Centre, Vegreville, AB, and Canadian Forest Service, Edmonton, $\mathrm{AB}$.

Thompson, I.D. and D.A. Welsh. 1993. Integrated resource management in boreal ecosystems - impediments and solutions. For. Chron. 69(1): 32-39.

Walters, C.J. 1986. Adaptive Management of Renewable Resources. McGraw Hill, New York.

Walters, C.J. 1998. Challenges in adaptive management of riparian and coastal ecosystems. Conservation Ecology (http://www.consecol.org) 1(2): 1.

Walters, C.J. and C.S. Holling. 1990. Large-scale management experiments and learning by doing. Ecology 71(6): 2060-2068.

Wagner, R.G., J. Flynn, R. Gregory, C.K. Mertz and P. Slovic. 1998. Acceptable practices in Ontario's forests: Differences between the public and forestry professionals. New Forests 16(2): 139-154. Weyerhaeuser, G.H. Jr. 1998. The challenge of adaptive forest management: Aren't people part of the ecosystem too? For. Chron. 74(6): 865-870. 